\title{
Simbol Binatang Ternakan dan Konsep Artifak sebagai Manifestasi Identiti Budaya dan Identifikasi Etnik Peribumi Sabah: Satu Kajian dari Perspektif Komunikasi The Livestock Symbol and Artefact Concept as Manifestation of Cultural Identity and Ethnic Identification among Sabah Indegenous Society: A Study from the Perspective of Communication
}

\author{
HALINA SENDERA MOHD. YAKIN, \\ ANDREAS TOTU, \\ ROSMAH DERAK
}

\begin{abstract}
Pusat Penataran Ilmu \& Bahasa, Universiti Malaysia Sabah, Jalan UMS, 88400 Kota Kinabalu 'halina_sandera@yahoo.com, ${ }^{2}$ rosmahderak@gmail.com, ${ }^{3}$ andreast@ums.edu.my
\end{abstract}

\begin{abstract}
Abstrak Pemaparan identiti budaya serta identifikasi etnik masyarakat di Sabah menerusi manifestasi dan signifikasi simbol serta objek yang diaplikasikan dalam kehidupan berbudaya masyarakat adalah inti pati makalah ini. Penelitian bersifat kualitatif berkenaan mengaplikasikan teknik pengamatan dan temu bual mendalam selain kaedah kepustakaan. Bertunjangkan perspektif komunikasi khususnya komunikasi bukan lisan, penulis mendeskripsikan dan mensignifikasikan makna, fungsi dan kepentingan simbol serta artifak terhadap tiga etnik peribumi Sabah, iaitu Dusun, Bajau dan Murut. Selain berfungsi sebagai identifikasi etnik, simbol binatang ternakan serta artifak seperti lembu, kerbau, kuda, ikan, gong, tajau dan perahu juga turut memaparkan nilai-nilai sosial, material serta spiritual yang melingkari kehidupan berbudaya etnik-etnik berkenaan. Makalah ini diharap mampu memberi sumbangan positif dalam usaha mempromosi dan melestarikan unsur kebudayaan masyarakat terbabit.
\end{abstract}

Kata kunci: Identiti budaya, identifikasi etnik, etnik peribumi, Sabah, simbol, artifak, komunikasi bukan lisan.

Abstract The primary aim of this article was portraying the cultural identity and ethnic identification among the indigenous society of Sabah through the manifestation and signification of symbol and object being utilized in the society's cultural life. Along with library resources, the qualitative research applied participant observation and in-depth interview as well. Employing communication perspective especially non-verbal communication, the 
meaning, function and importance of the symbol and artefact among three indigenous ethnics of Sabah namely Dusun, Bajau and Murut have been described and signified. Apart from serving as ethnic identification, the animal symbols as well as artefacts of cattle, buffalo, horse, fish, gong, tajau and canoe also represent social, material as well as spiritual values that encircled the cultural life of the ethnics. This article is expected to deliver positive contribution in an effort to promote and sustain cultural domain of the society.

Keywords: Cultural identity, ethnic identification, indigenous ethnic, Sabah, symbol, artefact, non-verbal communication.

\section{PENGENALAN}

Negeri Sabah bukan hanya terkenal dengan keindahan alam semula jadinya, tetapi juga kaya dengan kerencaman penduduknya yang terdiri daripada pelbagai kelompok etnik. Keragaman tersebut disebabkan kewujudan variasi dari pelbagai aspek budaya. Dari sudut statistik, penduduk peribumi Sabah diklusterkan kepada empat kumpulan etnik utama yang mendominasi saiz populasi negeri Sabah, iaitu kelompok etnik Dusun, Murut, Bajau dan Melayu sebagaimana diilustrasikan dalam jadual berikut. Selain daripada empat kelompok primer tersebut, Sabah turut dihuni oleh pelbagai golongan penghijrah dari serata dunia terutamanya dari Filipina, Indonesia dan beberapa negara Asia yang lain. Setiap kelompok etnik, sama ada kelompok majoriti ataupun minoriti masing-masing memiliki keunikan corak kehidupan, bahasa dan dialek, norma dan nilai-nilai moral, kepercayaan dan agama serta tradisi budaya yang menyumbang kepada perkembangan identiti budaya mereka. 
Jadual 1 Statistik penduduk Sabah pada tahun 2010 mengikut kelompok etnik

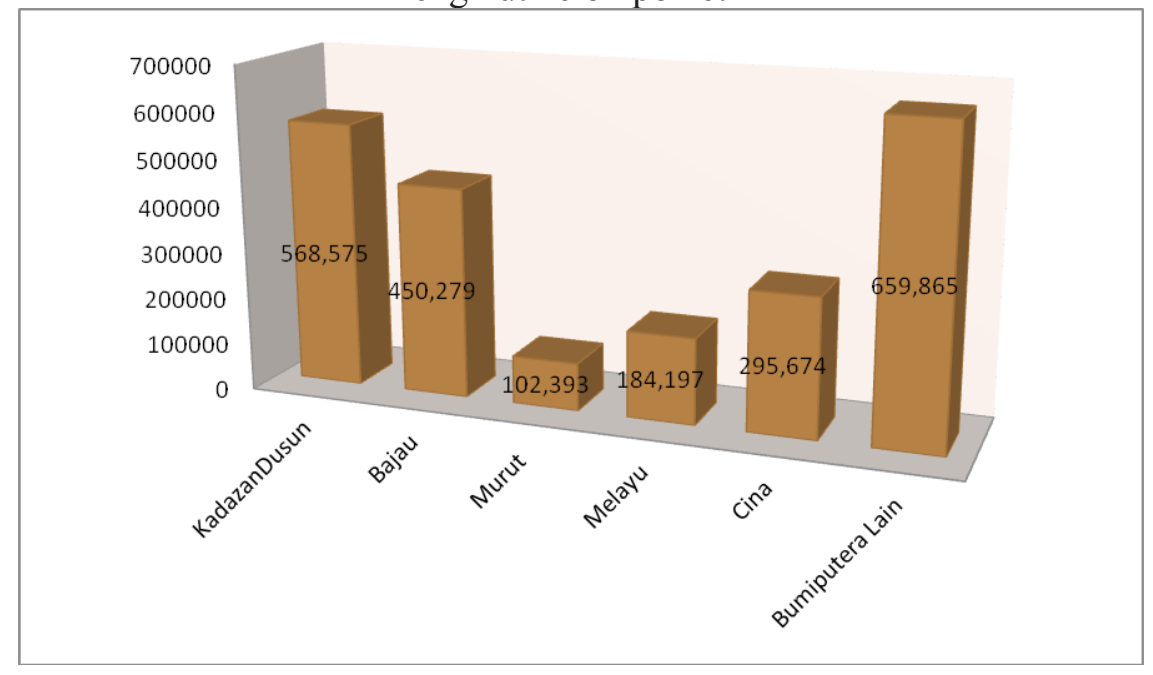

Sumber: Buku Perangkaan Tahunan 2014

Identiti budaya boleh diibaratkan sebagai lambang atau jati diri seseorang individu atau sesuatu komuniti yang bermaksud perkongsian sesuatu nilai dalam kehidupan manusia seharian yang merangkumi aspek bahasa, tingkah laku, corak kehidupan, amalan dan adat istiadat, norma serta nilai-nilai moral dan sebagainya. Ia dapat mencerminkan, mencorakkan dan membentuk diri serta tingkah laku individu dalam satu kumpulan budaya, di samping memberi panduan dalam kehidupan seharian. Identiti budaya adalah sesuatu yang sukar untuk diubah atau dibuang kerana identiti tersebut telah dipelajari atau dipraktikkan dalam diri individu sejak awal lagi, sama ada secara formal atau tidak formal (Halina Sendera, 2003; 2005; 2007). Identiti budaya masyarakat boleh diekspresikan menerusi pelbagai cara. Salah satu kaedah ialah dengan menggunakan saluran komunikasi lisan, iaitu dengan penggunaan perkataan, yakni pertuturan (informasi menggunakan vokal) ataupun penulisan (informasi secara non-vokal seperti dokumentasi bersifat manuskrip ataupun makalah). Selain itu, identiti budaya juga boleh dimanifestasikan menerusi saluran komunikasi tanpa lisan yang bersifat simbol serta objek. 
Sehubungan dengan itu, penulisan ini diusahakan untuk menyingkap penggunaan simbol binatang ternakan dan artifak sebagai satu cara untuk memaparkan identiti budaya dan identifikasi etnik peribumi di Sabah, iaitu etnik Dusun, Bajau dan Murut dengan memerikan persoalan-persoalan berhubung dengan pengertian dan fungsi artifakartifak tersebut dalam kehidupan dan budaya masyarakat terbabit. Artifak dan simbol binatang ternakan yang sering dikaitkan dengan kelompok peribumi di Sabah adalah seperti artifak gong, kerbau dan tajau bagi etnik Dusun; Kuda bagi etnik Bajau Kota Belud; Ikan dan perahu bagi etnik Bajau Semporna; Tajau bagi etnik Murut dan sebagainya. Makalah ini merupakan satu penelitian awal yang menggunakan kaedah pengamatan, temu bual mendalam dan kaedah kepustakaan.

\section{Perspektif Teori: Konsep Komunikasi Lisan dan Komunikasi Tanpa Lisan}

Komunikasi yang berasal daripada bahasa Latin, iaitu 'Communicare' ataupun secara literalnya bermaksud mewujudkan persamaan (to make common) dapat dimaknai secara universal sebagai satu proses pengiriman mesej daripada seorang sumber (atau lebih), kepada seorang penerima (atau lebih) menerusi satu saluran (atau lebih) agar sesuatu tindakan atau urusan dapat dicapai atau dilaksanakan. Ia adalah satu proses simbolik, interpretif (memberi tafsiran), transaksional komunikatif (pertukaran atau pengiriman dan penerimaan mesej secara berterusan) dan mengikut konteks di mana manusia membina makna-makna yang dikongsi bersama (Lustig \& Koester, 2003). Ia juga disifatkan sebagai satu proses di mana individu memberi respons atau bertindak balas dan membina mesej untuk mengadaptasikan diri dengan persekitaran dan juga antara satu sama lain (Samovar \& Porter, 2004). Dalam pengertian ini, komunikasi dianggap sebagai satu medium perkongsian dan pembinaan makna menerusi interaksi simbolik manusia (Seiler \& Beall, 2005). 


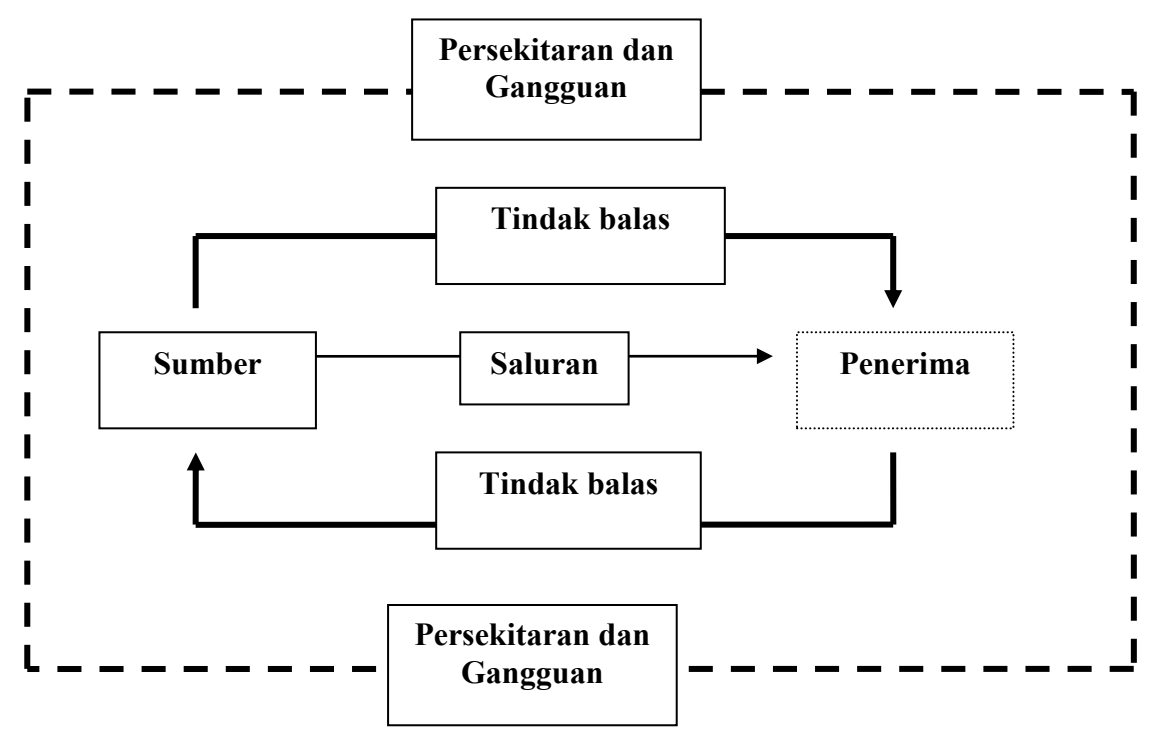

Sumber: Adaptasi daripada model-model komunikasi yang terdapat dalam buku Seiler, W.J. \& Beall, M.L. (2005)

Rajah 1 Model asas komunikasi

Dalam konsep yang luas, komunikasi dikatakan telah berlaku apabila sesuatu makna atau mesej disampaikan melalui pelbagai cara dan bentuk. Maknanya, komunikasi bukan hanya melibatkan simbol yang berbentuk lisan sahaja (penggunaan perkataan), malah ia juga merangkumi aspek yang tersirat, iaitu sebarang perlakuan, lambang atau simbol yang menimbulkan pengertian dan makna serta memerlukan penginterpretasian yang lebih mendalam. Justeru, komunikasi diklasifikasikan kepada dua, iaitu komunikasi lisan dan komunikasi tanpa lisan. Komunikasi lisan merujuk kepada simbol yang mempunyai makna universal kepada individu yang terlibat dalam proses komunikasi dan ia wujud dalam bentuk pertuturan dan tulisan yang dikenali sebagai bahasa (Barker, 1984). Dalam pemahaman ini, komunikasi lisan adalah komunikasi yang melibatkan perkataan, sama ada yang bersifat pertuturan ataupun percakapan (oral) dan juga penulisan (non-oral), yakni melibatkan aspek linguistik yang bertunjangkan kepada bahasa sebagai medium bagi membolehkan masyarakat berinteraksi, 
berkomunikasi dan mengkonsepsualisasikan dunia persekitaran mereka.

Komunikasi tanpa lisan pula mempunyai pengertian yang lebih mendalam. Ia didefinisikan sebagai "communication without words", yakni komunikasi tanpa perkataan (Adler \& Rodman, 2003; DeVito, 2005; Tubbs \& Moss, 2006). Justeru, komunikasi tanpa lisan ialah segala bentuk komunikasi selain daripada komunikasi yang menggunakan perkataan seperti definisi-definisi yang diutarakan oleh sarjana-sarjana seperti Ronald Adler dan George Rodman (2003:150) yang mengistilahkan komunikasi tanpa lisan sebagai "oral and nonoral messages expressed by other than linguistic means". Dalam pengertian ini, mesej bahasa seperti perkataan bertulis yang tidak diujarkan atau dituturkan secara vokal atau yang berunsurkan linguistik tidak termasuk dalam konsep ini tetapi tergolong dalam komunikasi lisan khususnya komunikasi yang tidak divokalkan kerana menurut Stewart Tubbs dan Sylvia Moss (2006) komunikasi tanpa lisan hanya "conveys nonlinguistic messages". Seperti juga komunikasi lisan, komunikasi tanpa lisan merangkumi kedua-dua komunikasi vokal (iaitu melalui penggunaan mulut) dan komunikasi tanpa vokal (non-vokal). Untuk menjelaskan kontinum tersebut, jadual berikut diaplikasikan bagi menjelaskan perbezaan antara komunikasi lisan dan komunikasi tanpa lisan.

\begin{tabular}{|l|l|l|}
\hline \multicolumn{2}{|c|}{ Jadual 1 Jenis-jenis komunikasi } \\
\hline \multicolumn{2}{|c|}{ Komunikasi vokal } & Komunikasi non-vokal \\
\hline $\begin{array}{l}\text { Komunikasi } \\
\text { lisan/verbal }\end{array}$ & $\begin{array}{l}\text { Perkataan yang } \\
\text { dituturkan (spoken } \\
\text { words) }\end{array}$ & Perkataan bertulis (written words) \\
\hline $\begin{array}{l}\text { Komunikasi } \\
\text { tanpa lisan/non- } \\
\text { verbal }\end{array}$ & $\begin{array}{l}\text { Nada suara, kualiti } \\
\text { vokal, keluhan, jeritan } \\
\text { dan sebagainya }\end{array}$ & $\begin{array}{l}\text { Gerak geri badan, pergerakan, } \\
\text { penampilan, ekspresi wajah dan } \\
\text { sebagainya }\end{array}$ \\
\hline
\end{tabular}

Jadual ini diadaptasikan dari Roland, B.A \& Rodman, G. (2003). Understanding Human Communication. New York: Oxford University Press yang terdahulunya diadaptasikan dari Stewart, J \& D’Angelo, G. (1993). Together: Communicating Interpersonally

Para sarjana telah mengkategorikan komunikasi tanpa lisan kepada beberapa jenis. Kesimpulannya, komunikasi tanpa lisan dapat dibahagikan kepada aspek komunikasi yang melibatkan ekspresi wajah, gerak isyarat, pergerakan badan atau kinesik (kinesics), pergerakan dan tingkah laku 
mata atau okulesik (oculesics), ciri-ciri fizikal, komunikasi sentuhan atau haptik (haptics), bau atau olfaktik (olfactics), penggunaan ruang atau proksemik (proxemics dan territoriality), penggunaan masa atau kronemik (chronemics), cara membunyikan atau menyuarakan perkataan yang diutarakan (paralanguage/vocalics), bunyi diam/berdiam diri (silence) konteks persekitaran yang melibatkan keadaan fizikal dan psikologikal, artifak (Wood, 2006; Seiler \& Beall, 2005; Jandt, 1995; Borden, 1991), pakaian dan penampilan fizikal (Adler \& Rodman, 2003; Jandt, 1995; Borden, 1991) kod rasa dan makanan atau gustik (gustics), kod muzik serta bunyian atau akustik (accoustics) dan tanda serta simbol (Jandt, 1995; Borden, 1991; Halina Sendera Mohd. Yakin, 2012; 2014).

Dalam penulisan ini, hanya aspek simbol atau tanda dan artifak yang akan disentuh untuk memperlihatkan komunikasi tanpa lisan dalam memaparkan identiti budaya dan identifikasi etnik peribumi Sabah. Dalam konteks komunikasi tanpa lisan, simbol atau tanda diertikan sebagai sesuatu yang mewakili atau melambangkan sesuatu yang mempunyai pengertian tersendiri, manakala artifak bermaksud sebarang objek atau barang milik peribadi (selalunya berbentuk material) yang boleh memberikan informasi tentang seseorang atau sesuatu sebagai contoh, harta benda, cara berpakaian, cara perapian diri dan sebagainya. Dalam konsep yang luas, sekiranya ia dikaitkan dengan budaya masyarakat, secara simboliknya, artifak tersebut dapat memberikan informasi tentang identiti budaya sesuatu kaum. Sehubungan dengan itu, penulis akan menjelaskan dalam perbincangan selanjutnya simbol binatang ternakan serta artifak-artifak yang dapat menggambarkan identiti budaya dan identifikasi tiga kelompok etnik peribumi utama di Sabah, iaitu etnik Dusun, Bajau dan Murut.

\section{Pemaparan Identiti Budaya dan Identifikasi Etnik Peribumi Sabah melalui Komunikasi Tanpa Lisan}

Bahagian ini dieksklusifkan untuk memberi deskripsi serta signifikasi berhubung makna, fungsi dan kepentingan simbol binatang ternakan serta artifak yang digunakan oleh etnik Dusun, Bajau dan Murut. 


\section{Simbol Kerbau serta Artifak Gong dan Tajau bagi Kelompok Etnik Dusun}

Kelompok etnik Dusun terdiri daripada pelbagai suku etnik, tetapi oleh kerana kekangan masa, penulis hanya mengkhusus kepada suku etnik Dusun Lotud di Tuaran. Bagi masyarakat Dusun, terdapat tiga objek atau artifak yang sangat diagungkan dalam budaya dan kehidupan mereka, iaitu kerbau, gong dan tajau. Tradisinya, ketiga-tiga objek atau artifak tersebut melambangkan kebanggaan, prestij dan status. Maknanya, sesiapa yang memiliki harta benda tersebut, orang itu dianggap golongan berada atau bangsawan dan dihormati oleh penduduk setempat. Lazimnya, harta benda tersebut dijadikan harta pusaka dan diwariskan secara turun-temurun.

Bagi masyarakat Dusun, kerbau mempunyai pelbagai fungsi dan kepentingan dalam kehidupan berbudaya mereka. Sumber mata pencarian utama bagi masyarakat ini ialah aktiviti bercucuk tanam, khususnya penanaman padi. Selain daripada itu, mereka juga mencari rezeki daripada hasil hutan dan laut. Maka, kerbau merupakan ternakan utama yang sangat diperlukan sebagai tunggangan harian dan juga untuk membantu dalam pembajakan sawah. Tambahan lagi, kerbau juga sering dijadikan korban untuk perayaan seperti Pesta Menuai (Tadau Kaamatan) dan juga upacara perkahwinan dan kematian. Dalam upacara perkahwinan, ia turut berfungsi sebagai 'berian' ataupun hantaran perkahwinan, khususnya daripada pihak lelaki. Dalam upacara kematian pula, masyarakat Dusun percaya bahawa kerbau yang dikorbankan tersebut secara simboliknya berperanan sebagai tunggangan roh si mati menuju ke syurga ${ }^{1}$. Di samping itu, kerbau juga digunakan dalam amalan 'sogit' yang bermaksud denda yang dikenakan kepada mereka yang melakukan kesalahan atau melanggar adat ${ }^{2}$ seperti melakukan zina, poligami dan menggali kubur dengan tujuan mengambil harta benda yang dikuburkan bersama si mati ${ }^{3}$, dan mengambil isteri orang ${ }^{4}$. Di samping itu, kerbau juga digunakan untuk 'tutup mulut', khususnya bagi mereka yang mengambil anak angkat. Dalam hal ini, pemberian kerbau disifatkan sebagai menutup mulut orang lain dari membuka rahsia perihal pengambilan anak angkat berkenaan. ${ }^{5}$ 
Selain kerbau, gong juga menjadi harta kebanggaan masyarakat Dusun. Selain berfungsi sebagai alat muzik tradisional yang mengiringi sesebuah majlis, gong juga digunakan dalam upacara sosial atau keramaian seperti perkahwinan dan kematian. Seperti kerbau, gong (iaitu gong asli yang tebal dan berat) juga digunakan sebagai 'berian' yang dikenali sebagai 'binubok'. Pukulan gong juga membawa pengertian yang tersendiri. Sekiranya terdengar gong dipukul sebanyak tiga kali, itu bermakna ada peristiwa buruk berlaku di kampung tersebut seperti ada kematian, kebakaran atau malapetaka yang lain. Sebaliknya, ketika upacara kenduri kematian diadakan, gong tidak boleh dipukul sama sekali sebagai tanda menghormati si mati dan keluarganya. Di samping itu, gong juga boleh digunakan untuk membayar denda 'sogit' ${ }^{6}$

Satu lagi artifak yang menjadi kebanggaan masyarakat Dusun ialah tajau. Tajau yang sering diagungkan dinamakan sebagai 'Gusi besar' kerana nilainya yang tinggi. 'Gusi' sering digunakan untuk upacara pemujaan, terutamanya pemujaan roh leluhur nenek moyang. 'Gusi' tersebut mempunyai pelbagai nama seperti 'Raja Intan', 'Penimbang Dapu', 'Monggison', 'Nunukon' dan sebagainya. Keragaman nama diambil sempena cerita di sebalik penemuan tajau berkenaan. Contohnya, nama 'Monggison' diberi kerana pemiliknya menemui tajau tersebut di atas pokok manggis. Demikian juga 'Nunukon' yang dikatakan ditemui di atas pokok 'nunuk' ataupun dikenali sebagai pokok ara. 'Gusi' dikatakan mempunyai penunggu dan akan diberi makan sempena upacara besar-besaran yang dipanggil sebagai 'Mangahaw'. Hal ini disebabkan pada masa dahulu, orang Dusun yang telah mati akan dimasukkan ke dalam tajau 'Gusi' yang bermulut besar sebagai ganti keranda. Lazimnya, upacara ini diadakan selama tujuh hari, tujuh malam setiap lima tahun sekali. Dalam upacara tersebut, kerbau akan dikorbankan dan diserikan dengan nyanyian dan tarian tradisional. Saudara-mara yang meraikan upacara 'Mangahaw' akan membawa tajau 'Gusi' masing-masing yang akan dikumpulkan dalam satu tempat khas sebelum upacara pemujaan yang diketuai oleh bobolian ${ }^{7}$. Di samping itu, tajau juga dijadikan hadiah bagi melambangkan perdamaian antara dua pihak yang bertelagah. Seperti kerbau dan gong, tajau turut digunakan untuk membayar denda 'sogit'. 


\section{Artifak Kuda, Lembu dan Kerbau bagi Kelompok Etnik Bajau Kota Belud}

Masyarakat Bajau di Sabah umumnya diklasifikasikan kepada dua, iaitu Bajau Pantai Barat dan Bajau Pantai Timur. Majoriti masyarakat Bajau di pantai barat tinggal di daerah Kota Belud manakala di sebelah Pantai Timur, sebilangan besarnya menduduki Semporna. ${ }^{9}$ Masyarakat Bajau di Kota Belud dikenali juga dengan gelaran Bajau Darat, manakala masyarakat Bajau Semporna lebih sinonim dengan gelaran Bajau Laut. ${ }^{10}$ Perbezaan identifikasi tersebut dapat diperlihatkan melalui perbezaan artifak yang menjadi kebanggaan dan simbol identiti mereka. Bagi masyarakat Bajau Kota Belud, simbol identiti budaya mereka dapat digambarkan melalui artifak atau binatang tunggangan, iaitu kuda, lembu dan kerbau. Ketigatiga binatang ini memainkan peranan yang amat penting dalam budaya masyarakat Bajau, khususnya di Kota Belud.

Bagi masyarakat luar yang pertama kali datang ke daerah Kota Belud, secara tidak langsung mereka boleh mengetahui serba sedikit tentang identiti budaya dan identifikasi kaum yang mendominasi daerah Kota Belud, iaitu kaum Bajau melalui artifak kuda yang terletak di Pekan Kota Belud. Artifak kuda tersebut dibina di tempat yang strategik, iaitu di laluan masuk ke Pekan Kota Belud sebagai menyambut kedatangan pengunjung dari luar daerah Kota Belud. Artifak kuda tersebut membawa maksud bahawa masyarakat Bajau Kota Belud merupakan penunggang kuda yang mahir. Disebabkan kemahiran tersebut, mereka mendapat jolokan nama 'cowboy of the east'. Sehingga hari ini, kehebatan masyarakat Bajau menunggang kuda masih terserlah sehingga ia menjadi salah satu acara terpenting dalam perayaan Tamu Besar Kota Belud ${ }^{11}$ yang diadakan setiap tahun. Dalam perayaan itu, masyarakat Bajau atau peserta yang terlibat akan melakukan persembahan dengan menunjukkan kehebatan mereka menunggang kuda dalam beberapa aksi menarik $^{12}$.

Kerbau dan lembu juga merupakan binatang yang sangat penting dalam kehidupan masyarakat Bajau bukan sahaja kerana fungsinya dalam membantu kegiatan penanaman padi dan juga sebagai sumber makanan. Malah, ia sangat berguna terutamanya dalam adat perkahwinan masyarakat Bajau. Lazimnya, kedua-dua binatang berkenaan digunakan sebagai 
'berian' ataupun hantaran perkahwinan daripada pihak lelaki kepada pihak perempuan selain barang keperluan pengantin, wang hantaran dan mas kahwin. Jumlah lembu atau kerbau untuk dijadikan 'berian' adalah bergantung kepada kemampuan pihak lelaki dan permintaan pihak perempuan. Bagi orang Bajau, kerbau atau lembu melambangkan kekayaan dan status. Tradisinya, mereka yang mempunyai banyak haiwan ternakan seperti lembu dan kerbau dianggap sebagai golongan berada. Di samping itu, pertandingan kerbau juga dijadikan sebagai salah satu acara terpenting dalam perayaan Tamu Besar Kota Belud selain daripada pertandingan Ratu Sarimpak $^{13}$ dan juga aksi Penunggang Berkuda.

\section{Artifak Ikan dan Perahu bagi Kelompok Etnik Bajau Semporna}

Masyarakat Bajau Semporna boleh diklasifikasikan kepada dua, iaitu masyarakat Bajau (diikuti dengan nama berdasarkan asal usul nenek moyang dan juga dialek yang diaplikasikan seperti A'a Sampulna, A'a Ubian, A'a Kubang, A'a Binadan, A'a Simunul, A'a Sibutu, A'a Kagayan, A'a Sikubang dan sebagainya) (Pallesen, 1985) dan Bajau Laut ataupun kadang-kadang diistilahkan sebagai Sama Dilaut yang juga dikenali oleh masyarakat tempatan sebagai Palau'. Kalau di Pekan Kota Belud terdapat artifak kuda, di Pekan Semporna pula, terdapat artifak ikan yang besar. Artifak ikan berkenaan digunakan sebagai lambang untuk menyampaikan mesej bahawa kehidupan dan budaya masyarakat di situ adalah bersumberkan laut atapun mempunyai afiliasi akrab dengan dunia pelayaran. Dalam erti kata lain, masyarakat Bajau Semporna terkenal sebagai nelayan dan pelayar laut yang mahir (Mohd Saffie, 2012; Halina Sendera, 2007; Saidatul Nornis, Halina Sendera, Mohammad Shauki \& Mohd. Rizal, 2012).

Di samping itu, masyarakat Bajau Semporna juga terkenal dengan seni bina perahu, yang lebih dikenali sebagai lepa. Lepa merupakan simbol keagungan, survival dan juga warisan budaya tradisi masyarakat Bajau di Semporna. Tradisinya, lepa berukuran 5 meter panjang dan 1.5 meter lebar dan berperanan sebagai alat pengangkutan, sumber rezeki dan kediaman masyarakat Bajau laut ataupun Palau'. Malah, sehingga kini masih ramai orang Palau' yang tinggal di dalam perahu yang diibaratkan sebagai rumah. Kira-kira sedekad lepas (semasa penulis menjalankan kajian lapangan di 
situ pada tahun 2005), terdapat kira-kira 50 perahu yang masih digunakan sebagai tempat tinggal orang Palau' yang mewakili dalam anggaran 50 keluarga. Satu perahu boleh menampung kira-kira 10 orang (Halina Sendera 2005; 2007).

Menurut responden kajian, orang Palau' pada masa dahulu tinggal di dalam bayanan yang dikenali sebagai lepa, barutu atau kubu-kubu $u^{14}$. Selain daripada dijadikan tempat tinggal, bayanan yang lebih besar seperti lepa turut berfungsi sebagai artifak untuk mencari nafkah di laut. Satu bayanan yang besar terdiri daripada beberapa bahagian dan bahagian-bahagian ini dicantumkan dengan menggunakan pasak kayu. Bahagian tengah yang mendominasikan keluasan sesebuah bayanan dijadikan sebagai ruang untuk beristirahat (iaitu ruang tamu dan tempat tidur), manakala bahagian buritan selalunya dijadikan tempat untuk memasak dan menyimpan barang makanan. Bahagian tengah bayanan selalunya berlantaikan papan yang boleh ditanggalkan bertujuan untuk menyimpan ikan di bawah geladak atau dek dan juga untuk menimba air dari perahu (Halina Sendera, 2005; 2007).

Oleh kerana kepentingannya, lepa dijadikan sebagai satu artifak unik dan menjadi salah satu aset ekonomi utama bagi daerah Semporna. Sebagai usaha untuk melestari, memperingati dan mempromosikan kepentingannya kepada generasi seterusnya dan juga masyarakat umum lainnya, daerah Semporna mengadakan sambutan pesta tahunan yang dikenali sebagai Perayaan Regatta Lepa ${ }^{15}$. Perayaan ini juga diperkasakan untuk menghargai pembuat, pengukir dan pengusaha lepa sama ada secara komersil ataupun sebaliknya kerana salah satu acara terpenting dalam pesta tersebut adalah pertandingan lepa tercantik. Lepa juga sering digunakan untuk memeriahkan majlis perkahwinan dan juga persembahan kebudayaan.

\section{Artifak Tajau bagi Masyarakat Murut}

Di Sabah, etnik Murut sangat sinonim dengan artifak tajau. Malah, ia telah menjadi identiti bagi etnik tersebut. Tajau memainkan peranan yang penting dalam kehidupan dan budaya masyarakat Murut kerana melambangkan kekayaan dan kehidupan mereka dari lahir sehinggalah jasad mereka terpisah dari bumi. Lantaran itu, seperti juga orang Dusun pada masa lampau, 
orang Murut yang meninggal dunia juga akan disemadikan di dalam tajau (takar) yang besar dengan kedudukan mayat yang diletakkan dalam posisi duduk dan kaki dilipat. Selain adat kematian, adat perkahwinan juga banyak menggunakan tajau yang berlainan jenis seperti tajau 'Tiluan' dan 'Binungkul' yang digunakan dalam upacara peminangan, dan tajau 'Tabu Maong' dan 'Rubi Abai' yang berfungsi sebagai 'berian' atau hantaran perkahwinan. Tajau dipercayai mempunyai semangat yang mampu membawa bukan sahaja kebaikan kepada pemiliknya, malah berupaya mengundang bencana. Namun tidak semua tajau mempunyai semangat, kecuali tajau yang mempunyai lamai seperti tajau Tiluan, Minukul dan Belayong (Abdul Hakim, 2005).

\section{PENUTUP}

Makalah yang dihasilkan daripada penelitian awal penulis telah diikhtiarkan untuk memaparkan komunikasi tanpa lisan dalam identiti dan identifikasi budaya peribumi utama di Sabah, iaitu etnik Dusun, Bajau dan Murut. Artifak dan simbol binatang ternakan seperti kerbau, kuda, ikan, perahu, gong serta tajau merupakan antara objek dan barangan yang mempunyai material dan sentimental value dan sering dikaitkan dalam kehidupan dan budaya kelompok etnik peribumi di Sabah. Secara simboliknya, artifak atau simbol tersebut mempunyai maksud tersirat yang secara tidak langsung menggambarkan identiti budaya masyarakat peribumi Sabah, di samping menyerlahkan identifikasi bangsa sesebuah kelompok etnik. Justeru, pengetahuan dan pemahaman tentang fungsi dan perlambangan artifak-artifak tersebut dalam kehidupan masyarakat haruslah disematkan di jiwa dan minda agar khazanah tersebut tidak lapuk ditelan zaman, dan dapat diwariskan sebagai khazanah berharga untuk generasi mendatang. 


\section{NOTA}

1 Dalam hal ini, kerbau jantan adalah menjadi keutamaan.

2 Untuk maklumat lanjut tentang hukuman sogit dan dendanya, sila rujuk Undang-Undang Mahkamah Anak Negeri.

3 Bagi kesalahan tersebut, dendanya adalah satu ekor kerbau.

4 Bagi kesalahan tersebut, dendanya adalah tiga ekor kerbau kerana dianggap kesalahan berat.

5 Temu bual dengan Ketua Kampung Bantayan, Tamparuli, Tuaran, iaitu Encik Antakin bin Andau.

6 Temu bual bersama Puan Tialan Sindum dan anaknya, Puan Jerih Unnung di rumah kediaman mereka di Kampung Bantayan, Tamparuli.

7 Bobolian ialah bomoh yang mengetuai sesuatu amalan adat resam

8 Sogit bermaksud denda ataupun boleh diertikan sebagai saman yang dikenakan terhadap individu yang melakukan kesalahan atau melanggar adat yand dipraktikkan masyarakat Dusun dan Murut.

9 Perbezaan lokasi utama berkenaan telah menyebabkan wujudnya pengklasifikasian terhadap suku etnik Bajau di Sabah, iaitu orang Bajau Pantai Barat dan orang Bajau Pantai Timur. Selain itu, sarjana Barat juga sering merujuk orang Bajau Pantai Barat sebagai Bajau Darat, manakala orang Bajau Pantai Timur sebagai Bajau Laut. Pengklasifikasian berkenaan turut diterima pakai oleh kerajaan yang antaranya bertujuan memudahkan pembezaan kelompok-kelompok terbabit, termasuklah dalam urusan melibatkan bancian penduduk. Hakikatnya, orang Bajau Pantai Barat lebih selesa mengidentifikasikan diri mereka sebagai Jomo Sama, manakala orang Bajau Pantai Timur gemar menggunakan istilah A'a Sama yang kedua-duanya bermaksud orang Sama atau orang Bajau. Dalam pemahaman ini, perlu dimaklumi bahawa identiti takrifan pihak pemerintah terhadap sesuatu kelompok etnik tidak semestinya selaras dengan identiti takrifan harian yang dikonstruk sendiri oleh ahli-ahli kelompok berkenaan (Halina Sendera 2007; Saidatul Nornis, Halina Sendera, Mohammad Shauki dan Mohd. Rizal, 2012).

${ }^{10}$ Namun demikian, masyarakat Bajau Kota Belud lazimnya mengidentifikasikan diri mereka sebagai Sama Kuta Belud yang bermaksud orang Bajau Kota Belud.

11 Tamu Besar kota Belud merupakan satu perayaan pasar terbuka yang terbesar di Sabah. Ia menyajikan kepelbagaian budaya Kota Belud yang diserikan dengan pelbagai persembahan dan kegiatan perdagangan.

${ }_{12}$ Persembahan penunggang kuda dengan aksi menarik bermaksud peserta yang mengambil bahagian akan mempamerkan kemahiran menunggang dan mengawal kuda yang dihiasi dengan pakaian serta hiasan berwarni warni berdasarkan warisan budaya masyarakat Bajau.

${ }^{13}$ Ratu Sarimpak ialah salah satu acara pertandingan dalam temasya tamu besar Kota Belud yang disertai oleh gadis-gadis Bajau. Istilah Ratu Sarimpak diambil sempena hiasan kepala bagi wanita Bajau tradisi, iaitu Sarimpak (ada kalanya disebut juga sebagai Serimpak). Ia lazimnya dipakai oleh wanita atau gadis Bajau semasa perkahwinan, persembahan tarian dan dan juga majlis-majlis keramaian. Para peserta dalam pertandingan Ratu Sarimpak akan menggunakan hiasan kepala berkenaan dan juga pakaian tradisi Bajau. Biasanya, pemenang diadili berdasarkan kecantikan, gaya serta tingkah laku dan kebijaksanaan.

${ }_{14}$ Lepa, barutu dan kubu-kubu adalah jenis-jenis perahu yang digunakan oleh orang Palau' sebagai tempat tinggal.

15 Perayaan ini diadakan pada bulan April saban tahun sejak tahun 1994. Pada mulanya, ia hanyalah dianggap sebagai sambutan tahunan peringkat daerah, sehinggalah diiktiraf sebagai aktiviti peringkat negeri Sabah. Kini, ia telah dijadikan sebagai salah satu pesta tahunan Malaysia. 


\section{RUJUKAN}

Abdul Hakim Mohad. (2005). Tajau dan peranannya dalam budaya masyarakat Murut di Tenom, Sabah. Jurnal Peradaban Melayu, Vol.3, hlm. 61 - 69.

Abdul Rahman Ahmad Hanafiah. (2004). Komunikasi budaya: Dari alam rahim ke alam barzakh. Kuala Lumpur: Dewan Bahasa dan Pustaka.

Adler, R.B. \& Rodman, G. (2003). Understanding human communication (8 ${ }^{\text {th }}$ ed). New York: Oxford University Press.

Barker, L.L. (1984). Communication. New Jersey: Prentice-Hall.

Barthes, R. (1964). Elements of semiology. (Lavers, A. \& Smith, C. Trans.). New York: HILL and WANG. (Original work published 19).

Bonvillain, N. (1993). Language, culture, and communication: The meaning of messages. New Jersey: Prentice Hall, Inc.

Borden, G. A. (1991). Cultural orientation: An approach to understanding intercultural communication. New Jersey: Prentice Hall.

Buku Tahunan Perangkaan Sabah 2014.

Chandler, D. (2002). Semiotics: The basics. London: Routledge.

Dayu bin Sansalu. (2002). Pendidikan dan Proses Pemodenan masyarakat Dusun di Sabah (1881 - 1967). Tesis Doktor Falsafah tidak diterbitkan, Sekolah Sains Sosial, Universiti Malaysia Sabah.

DeVito, J.A. (2005). Essentials of human communication ( $5^{\text {th }}$ ed). Boston: Pearson.

Druckman, D., Rozelle, R.M. \& Baxter, J.C. (1982). Nonverbal communication: Survey, theory and research. Beverly Hills: SAGE Publications.

E.K.M. Masinambow \& Rahayu S. Hidayat. (2001). Semiotik: Mengkaji tanda dalam artifak. Jakarta: Balai Pustaka.

Gimfil, J. (1983). The Kadazan at the crossroads. Kuala Lumpur: Penampang Kiti Trading.

Halina Sendera Mohd. Yakin (2003). Akulturasi imigran Filipina generasi pertama dan kedua di Sabah. Kota Kinabalu: Universiti Malaysia Sabah.

Halina Sendera Mohd. Yakin. (2005). Budaya tradisi kelompok etnik Palau' di Semporna, Sabah. Jurnal Manu, Bil. 10, hlm. 106-118.

Halina Sendera Mohd. Yakin. (2007). Identiti budaya etnik Palau' di Semporna, Sabah: Konservasi, adaptasi dan transformasi budaya. Kota Kinabalu: Universiti Malaysia Sabah.

Halina Sendera Mohd. Yakin. (2012). Symbolism in the death ritual among the Bajaus. The International Journal of the Humanities, Vol. 9 (10), hlm. 71-84.

Halina Sendera Mohd. Yakin. (2013). Manifestasi identiti budaya Bajau menerusi simbolisme dalam perkahwinan dan kematian. Dlm. Saidatul Nornis Mahali (Ed.), Sistem Nilai dan Norma Etnik Sabah (hlm. 85-106). Kota Kinabalu: Penerbit Universiti Malaysia Sabah. 
Halina Sendera Mohd. Yakin \& Andreas Totu. (2014). Signifikasi konsep proxemics dan chronemics dalam ritual kematian Bajau: Satu Kajian dari perspektif komunikasi bukan lisan. Jurnal Komunikasi UKM-Malaysian Journal of Communication, Vol. 30 (2), hlm. 71-90. Bangi: Universiti Kebangsaan Malaysia.

Hall, E. T. (1959). The silent language. USA: A Fawcett Premier Book.

Hall, E. T. (1966). The hidden dimension. New York: DOUBLEDAY.

Jandt, F.E. (1995). Intercultural communication: An introduction. London: Sage Publication.

Jehom, W.J. (1999). Ethnicity and ethnic identity in Sarawak. Akademika, Vol. 55, hlm. 83-98.

Jun, A. 2005. Sama (Bajau). Dlm. Adelaar, A. \& Himmelmann, N.P. (Ed.). The Austronesian Languages of Asia and Madagascar. London: Routledge.

Leach, E. (1976). Culture and communication: The logic by which symbols are connected. Cambridge: Cambridge University Press.

Leeds-Hurwitz, W. (1993). Semiotics and communication: Sign, codes, cultures. New Jersey: Lawrence Erlbaum Associates, Publishers.

Masinambow, E.K.M. \& Rahayu S. Hidayat. (2001). Semiotik: Mengkaji tanda dalam artifak. Jakarta: Balai Pustaka.

Peterson, J., Nelson, P., Titsworth, S., \& Harter, L. (2006). Human communication ( $\left.2^{\text {nd }} E d.\right)$. Boston: McGraw-Hill.

Samovar, L.A \& Porter, R.E. (2004). Communication between cultures. Australia: Thomson.

Segerstrale, U \& Peter, M. (1997). Nonverbal communication: Where nature meets culture. New Jersey: Lawrence Erlbaum Associates, Publishers.

Seiler, W.J. \& Beall, M.L. (2005). Communication: Making connections. Boston: Pearson.

Siti Aidah Hj. Lokin. (2003). Perubahan Sosioekonomi dan Pentadbiran Masyarakat Peribumi Sabah (1881 - 1963). Tesis Sarjana Sastera, sekolah Pendidikan dan Pembangunan Sosial, Universiti Malaysia Sabah.

Tubbs, S.L \& Moss, S. (2006). Human communication: Principles and contexts (10 $0^{\text {th }}$ ed.). Boston: McGraw-Hill.

Wood, J.T. (2006). Communication mosaics. An introduction to the field of communication ( $4^{\text {th }} \mathrm{ed}$ ). Wadsworth: Thomson

Yuet See Monica Owyong. (2009). Clothing semiotics and the social construction of power relations. Social Semiotics. Vol. 19 (2), 191-211.

Zaleha Abu Hassan. (1996). Mak Yong sebagai wahana komunikasi budaya: Satu analisis mesej. Tesis Sarjana tidak diterbitkan, Universiti Kebangsaan Malaysia, Bangi. 


\section{Temu bual}

Antakin bin Andau, Ketua Kampung Bantayan, 16 Jun 2006 di Kampung Bantayan, Tamparuli.

Panglima Tiring bin Hawani dan isterinya, Amjatul, 20 September 2005 di Kampung Bangao-Bangao, Semporna.

Tialan Sindum dan anaknya, Puan Jerih Unnung, 16 Jun 2006 di Kampung, Bantayan, Tamparuli. 
